mercurial treatment that the disease was not derived from the affected cows. Again, in the medical journal just quoted ' notes of twenty-two cases communicated to the human suivject are given, in which the symptoms found divided themselves into two clasies-viz., those with fever acsompanied by constitutional symptoms only, and those with fever coupled with constitutional symptoms and rash on the hands and feet together with mouth ulceration. There i ; a further account in the same journal for $1875^{6}$ of cases ob served in Morayshire.

But little remains to be said regarding treatment. Believing, as I did, that the disease was of microbic origin dilute solutions of permanganate of potash and sanitas were used frequently as mouth washes, while small doses of quinine were administered internally. Nourishment in liquid form and in small quantities was freely given

Glasgow.

\section{A PLEA FOR EARLY OPERATION IN DILATED STOMACH DUE TO PYLORIC OR DUODENAT, OBSTRUCTION.}

BY RICHARD BEVAN, I.R C.P. LoNd, M.R.C.S. ENG., D.P.H.

HAVING had under my immediate and constant care one case of dilated stomach in which gastro-enterostomy had been performed nine months ago, and having had partial observation of another case under like circumstances, I have been favourably situated for watching their after history, the benefits accruing from the operation and the destructive results of the disease prior to operation. The experience thus gained may be of $\mathbf{c} \rightarrow$ in drawing some conclusions which may be of benefit to patients in like condition, more especially in those very successful cases in which the obstruction is due to non-malignant causes; consequently cases in which the operating cause has been prolonged in its course and gradual in its action.

Looking at the success-brilliant success-of the operation of gistro-enterostomy as now achieved by the majority of the surgeons who have practised it for the relief of dilated stomach as the result of pyloric or duodenal obstruction, may I, first and foremost, most strongly urge the earlier aduption of this operation as a curative measure? The treatment has for this complaint hitherto been far too medical and too little surgical. It has been the practice to recommend dieting, antiseptics, and lavage as palliative measures, and to urge the patient to persevere and jog along with these. They are, however, merely palliative. And I would urge, once and for all, that as soon as "dilated stomach" has been diagnosed, and as soon as marked gastric peristalsis is observed, whether by the surgeon or by the patient (and I would here observe that this may have been present for months or longer, and its importance not sufficiently apprec:ated by either unless carefully looked for and its presence and significance explained), then, and at once, I would recommend operative interference, for delay can only mean a serious prolongation of those destructive influences, which it will take months or even years to recover from, even if they do not cost the life of the patient. It was the result of this postponement of operation in one of the patients under notice that attracted my special attention and which urges me to recommend, as forcibly as I can, the eally adoption of the only radical means of cure which are $o p=n$ to the patient. In non-malignant cases the progress of the disease is insidious, very gradual, and is probably prolonged over years. In the early stages, while the obstruction is sight, very little, if any, food is retained in the stomach and the patient continues to be fairly nourished. This is probably due to the fact that compensatory hypertrophy lakes place in the muscular coats of the stomach at the same time as the dilatation. Later, however, there begins to be left bzhind at first a small residuum which ferments. This stagnating residuum is the commencement of a vi jiuas circle, for from it are evolved the gases so powerful in the production of increased dilatation

Ibid.. rol. ii., 1869, p. 536

Itbil., vol. it., 1875, p. 652

7 Cases of this affection in human beings were reported in

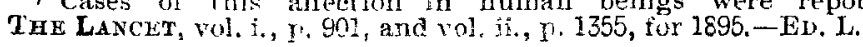

later, and from it are formed the acrid products which irritate the lining of the stomach, and, in addition, cause the further spasmodic contraction of the already obstructed pylorus. The further development of these symptoms tends to give the finishing touch to a long series of sufferings and distress which can only be ably described by one who has suffered. The patient begins to lose flesh; very little food is absorbed by the stomach (?) or reaches the duodenum ; he is anæmic, of an eartby colour; he is plagued with horrible eructations; he loathes food; appetite he has none and eating is pain and sorrow to him; he cannot sleep; he vomits ; his lassitude and exhaustion are distressing; he is poisoned with toxins and ptomaines, so that he is in constant danger of attacks of syncope; he is cold, nothing warms him ; his thirst is that of "Dives," and, like him, it cannot, dare not, be gratified or satisfied. At this time, owing to the enfeebled state of the body, to the lack of nourishment, and to its being enormously distended with gas, the product of fermentation, and with gallons of fluid, the secretion of the mucous glands, I should fancy that the pathological condition of the stomach is that of dilatation without hypertrophy, for it is with the greatest possible difficulty that it can be got to contract and dilatation increases apace. While this dilatation is going on an active destruction or atrophy of the peptic glands is proceeding; to this I shall allude later, for on the advancement of this destructive process may depend the future comfort and speed in recovery of the patient. Life under the above-mentioned circumstances is only endurable by continued lavage of the stomach by means of the syphon tube-say, twice a day or so; in fact, under this he may gain a pound or two in weight, but unless the surgeon soon comes to the rescue the faintest breath of disease may carry him off like a vapour. It is, then, this necessity of having early recourse to the operator before the final stage comes on, with all its attendant dangers and drawbacks, that I would most earnestly press on the practitioner in charge. Up to then the patient has not lost a great deal of flesh, his body is fairly nourished, his rallying power is not abolished, and, moreover, his local trouble has not advanced to such an extent that after the operation, the success of which he may reasonably look forward to, he may not find his stomach a wreck and his digestion a trouble.

Immediately after the operation among some of the drawbacks consequent upon this enfeebled or atonic condition of the stomach, the most pressing is the discomfort arising from the regurgitation of bile into the stomach through the new opening. This causes sickness (quite distinct from the anæsthetic), non-digestion of food, increased dilatation, and is a source of great distress and even danger to the patient, who is in dire need of the nourishment and strength it gives in order to tide over the operation. This difficulty may continue for weeks, or, as in my patient, for months afterwards. It is most prone to occur when the patient reclines, consequently more often at night, and especially if the stomach is distended with a considerable evening meal and he goes to bed before he gets rid of some of it. This seems to dilate the opening at the junction and readily allows of the entrance of the bile trom the bowel. No doubt the stomach contracts considerably directly after the operation, but until it obtains tone and strength it lacks much of the power of expelling the food into the bowel, and the entrance of bile seems to add to its incapacity. Sitting up or walking after each meal succeeds in averting some of the discomfort consequent on this trouble, but time after time it has had to be relieved by emptying and wasbing out the stomach by means of the syphon tube. Again, the want of digesting power owing to the destruction of the peptic glands is a fruitful source of trouble to the convalescent. The slightest over-feeding or over-distension in the quantity of either liquid or solid causes non-contraction, pain, fermentation, and all its attendant discomforts. These, again, are only to be relieved by syphonage and lavage. For months the slightest indiscretion in diet reminds the patient of his folly in imposing impossible tasks on his stomach, and it is only by living by rule and by the greatest care that he prevents life from still becoming a burden; yet notwithstanding all this the benefits conferred on both these patients were enormous, mainly by getting rid of some at least of the food that they put into the stomach, so that it reached the lacteals and veins of the intestine, for they gained flesh, colour, weight, energy, and courage almost at once. One patient returned to hard work in five weeks, and gained over $2 \mathrm{st}$. in weight in three months, the other $7 \mathrm{lb}$. in a fortnight; both, however, I am 
bound to say enjoyed freedom from discomfort only by the aid of once or twice a day using the syphon tube. By its use comfort was obtained, appetite restored, sleep returned, and gradual contraction of the stomach was secured.

Whether the atrophied glandular tissues of the stomach are ever entirely restored after the complete abolition of the destructive agencies at work I do not know, but I should suspect that their impairment is in direct ratio to the delay in the adoption of operative measures, and I should fancy that some repair of these structures at any rate is made by means of the careful and appropriate use of the syphon tube, for the digestive power has returned to such an extent that the occasion for its use is becoming less and less frequent during the nine months of convalescence, and these patients now live in comparative paradise. How much more of their present troubles could have been averted by earlier operation it is hard to say, but I am bound to believe a good deal. If we are willing to concede this, how much greater an influence would the adoption of earlier surgical assistance have had in preventing the patient's horrible sufferings, and in many cases in lessening the mortality statistics of this most beneficial operation?

Lydd, Kent.

\section{A CASE OF RAYNAUD'S DISEASE ASSOCIATED WITH URAMIA.}

\section{By C. CRAWFORD AITKEN, M.B., C.M. EDIN.}

I HAVE ventured to bring to the notice of the profession the following case, not merely because it is an example of the rare condition known as Raynaud's disease, but rather because it is a further instance of the association with the uric acid diathesis and embodies a hitherto, I believe, unrecorded clinical feature-viz., the association of uræmic exacerbations with the attacks of vaso-motor spasm.

The patient was a man aged forty-three years and came under observation in October, 1894. He had a well-marked gouty diathesis and albuminuria of more than six years' standing. His father, who had died from renal disease, was alcoholic and probably gouty; an elder brother suffered from sciatica; and the mother had been subject to epileptiform attacks. The patient was in good circumstances, regular in his habits, and very temperate both in food and drink, but for many years he had suffered occasionally from gout. He had never been abroad and there was no suspicion of syphilis. The kidney condition had been first diagnosed in 1889 as chronic interstitial nephritis. It had latterly grown worse; the average excretion of urea had dropped to 250 grains daily and there were the usual symptoms of chronic uræmic poisoning; but up to March, 1895 , there was no appearance of muscular twiching or convulsions. The symptoms of Raynaud's disease dated back to 1887, when the ears suffered paroxysmal attacks of cyanosis, numbness, and pain. These recurred at first as often as five or six times in the twenty-four hours, but afterwards became less frequent though more severe. No morphological change took place in the ears. Similar symptoms appeared in the fingers in April, 1888, and in the toes about four years later. The appearances were almost always bilateral, though not absolutely symmetrical. Cyanosis was always preceded by a stage of syncope with local pallor and coldness and subjective sensations of numbness and tingling. Then came the initial stage of asphyxia, with local hyperæsthesia, slight rise of temperature, and throbbing pain; and, as the parts became more highly discoloured, gradual, though in some cases rapid, loss of tactile sensation and constant aching pain. There was no relationship to any special nerve-supply, but it was interesting to note that as a rule the first and fifth digits were comparatively slightly affected. Mortification took place in the case of many of the digits, amputation occurring in the fingers at the second interphalangeal joint and in the toes generally at the first interphalangeal joint. It occupied in each case some three or four months. The case presented the usual cardio-vascular changes of chronic Bright's disease. The pulse showed increased tension during the attacks of arteriolar spasm, but there was no loss of force. Even on occasions when the cyanosis was unilateral the pulse in the radial, ulnar, dorsalis pedis, and posterior tibial vessels showed no difference on the two sides except the change in tension. The urine showed the renal excretion of urea to be never higher than 320 grains daily. It frequently contained a small amount of hæmoglobin, with about 0.3 per cent. albumin (Esbach) and numerous epithelial and granular casts. In connexion with the general nervous system there was little to be noted. There was great mental torpor and persistent exaggeration of the plantar and patellar reflexes. Albuminuric retinitis and swelling of the discs were apparent in each eye, and there were some small retinal hæmorrhages. The vascular spasm showed itself not only in the extremities. but also in the retinæ; and it is suggested that the vessels of the kidney were also implicated, as in the course of observations extending over some months it was found that the excretion of urea showed marked diminution during the attacks of cyanosis.

Table Shoming the Average Daily Excretion of Urea between and during Successive Attacks of Kaynaud's Disease.

\begin{tabular}{|c|c|c|c|c|}
\hline \multirow{2}{*}{$\begin{array}{l}\text { Date of } \\
\text { attack. }\end{array}$} & \multicolumn{2}{|c|}{$\begin{array}{l}\text { Average daily ex- } \\
\text { cretion of urea. }\end{array}$} & \multirow{2}{*}{\multicolumn{2}{|c|}{ Remarks. }} \\
\hline & $\begin{array}{l}\text { Between } \\
\text { attacks. }\end{array}$ & $\begin{array}{l}\text { During } \\
\text { attack. }\end{array}$ & & \\
\hline 1895. & & & & \\
\hline March 2nd ... & - & 280 & - & \\
\hline,$\quad 20$ th $\ldots$ & 320 & 200 & - & \\
\hline April 12th ... & 260 & 140 & Twitching marked. & Two fits. \\
\hline 9 th $\ldots$ & 280 & 200 & , & Two fits. \\
\hline $21 s t \ldots$ & 320 & 240 & No twitching. & \\
\hline 31st $\ldots$ & 280 & 160 & One fit. & \\
\hline June 13 th ... & 280 & 200 & One tit. & \\
\hline$\Rightarrow \quad 20 \operatorname{th} \ldots$ & 260 & 180 & One fit. & \\
\hline $28 \operatorname{th} \ldots$ & 240 & 120 & One fit. & \\
\hline 31st ... & 260 & 200 & One fit. & \\
\hline July 26 th ... & 200 & 120 & Several fits. Coma. & \\
\hline
\end{tabular}

Between May 21st and July 2nd, 1895, there were seven uræmic convulsive attacks, five of which had an apparent close relationship to the crises of concurring attacks of severe vascular spasm. On July 4th, 1895, the morning urine showed only four and three-quarter grains of urea per ounce. An attack of vaso-motor spasm commenced shortly afterwards, and showed itself not only in the extremities, but also to a very marked extent in the retinal vessels; and on July 6th, when it was at its height, uræmic convulsions occurred. The discolouration continuing, two more uræmic fits occurred on July 9th. Five minutes before the second fit the urine passed showed only 4 grs. of urea per ounce. Three hours after a further specimen showed 51 grs., and this proportion was maintained for some days, the retinal vessels regaining their normal size and the cyanosis in the extremities disappearing. Relapses, however, were frequent, and the patient slowly sank. On July 26 th intense cyanosis reappeared in the various digits and in the ears, several uræmic fits occurred in rapid succession, and the urine passed contained only $3 \mathrm{grs}$. of urea per ounce, the total daily secretion having sank to 120 grs. Within a week death took place from uræmic coma. The friends unfortunately refused to permit any necropsy.

With regard to the treatment of the case, it necessarily resolved itself largely into the treatment of the renal inadequacy; but, nevertheless, many means were tried for the control of the vaso-motor condition. Galvanism, as adrocated originally by Raynaud, was extensively employed, but I cannot say that any precise benefit resulted. Similarly, arsenic, chloral, strychnine, and nitrite treatment were apparently quite useless. The insomnia arising from the local pain and the exhaustion proved very intractable. Morphia and opiates were contra-indicated in the face of the kidney condition, and one was forced to fall back upon chloral, sulphonal, urethan, and bromides. Of these, the best was urethan; but in the later phases of the disease even this lost its effect, and recourse had to be had to chloral and small doses of morphia.

The remarkable concurrence of uræmic exacerbations and attacks of vascular spasm in this case seems to indicate at once some relationship. It seems scarcely possible that uræmia could occasion the vaso-motor phenomena. It is a condition of not infrequent occurrence, but the vascular condition such as is found in Raynaud's disease, though influenced to some extent by the gouty diathesis, is still a symptom of the rarest occurrence. On the other hand, it is 